\title{
Effect of Surface Treatment and Fiber Orientation on the Tensile and Morphological Properties of Banana Stem Fiber Reinforced Natural Rubber Composite
}

\author{
Ikechukwu Christian Ezema1 ${ }^{*}$, A. R. Ravindranatha Menon², Camelus Sunday Obayi1, \\ Augustin Dinobi Omah' \\ ${ }^{1}$ Department of Metallurgical \& Materials Engineering, University of Nigeria, Nsukka, Nigeria \\ ${ }^{2}$ National Institute for Interdisciplinary Science and Technology (NIIST), CSIR, Trivandrum, India \\ Email: ${ }^{*}$ ikeezema@gmail.com, drarrmenon@gmail.com, camiobayi@yahoo.com, dinobi2002@yahoo.com
}

Received 24 January 2014; revised 7 March 2014; accepted 17 March 2014

Copyright (C) 2014 by authors and Scientific Research Publishing Inc.

This work is licensed under the Creative Commons Attribution International License (CC BY).

http://creativecommons.org/licenses/by/4.0/

(c) (i) Open Access

\begin{abstract}
A mixture of $\mathrm{NaOH}$ and $\mathrm{Na}_{2} \mathrm{SO}_{3}$ was used in modification of banana stem fibers (BSF). Unidirectional BSF reinforced natural rubber (NR) lamina composites were made using compression moulding method. The results of the tensile loading in $0^{\circ}, 45^{\circ}$ and $90^{\circ}$ to the fiber directions of the composite with fiber mass fraction of $30 \%$ were studied. Surface modification of the BSF with a mixture of $4 \% \mathrm{NaOH}$ and $2 \% \mathrm{Na}_{2} \mathrm{SO}_{3}$ increased the tensile strength and elastic modulus of the composite to 4.03 MPa and 147.34 MPa respectively from 3.12 MPa and 84.30 MPa of the untreated. Variation in properties due to fiber orintations was observed indicating a higher value of properties in the $0^{\circ}$ fiber orientation than in $45^{\circ}$ and $90^{\circ}$ directions. The result of scanning electron microscope (SEM) micrographs of the surfaces of the fibers indicted an improvement in bonding of the fiber bundles prior to lamination with natural rubber as a result of surface treatment which resulted in its higher tensile strength.
\end{abstract}

\section{Keywords}

Natural Fiber, Banana Fiber, Natural Rubber, Tensile Properties, SEM, Fiber Orientation

\section{Introduction}

Development in materials transformation is on the increase particularly in composite technology due to their

"Corresponding author.

How to cite this paper: Ezema, I.C., et al. (2014) Effect of Surface Treatment and Fiber Orientation on the Tensile and Morphological Properties of Banana Stem Fiber Reinforced Natural Rubber Composite. Journal of Minerals and Materials Characterization and Engineering, 2, 216-222. http://dx.doi.org/10.4236/jmmce.2014.23026 
attractive properties. Again, the effect of climate change is here with us and as such governments all over the world are now very conscious of this and as such, efforts to replace synthetic materials with biodegradable products are welcomed. Natural fibers are fast replacing high performance fibers such as carbon, aramid and glass fibers in some semi-structural applications because of their biodegradability, renewability, low cost, specific stiffness and high degree of crystallinity [1]. This challenge has encouraged rapid progress in natural fiber reinforced composites research and development.

In the recent decades, research and reseachers on natural fibers are on the increase [2]-[5] with promising results on the mechanical properties of the natural fibers they worked on. Natural fibers can be used alone or as a hybrid in combination with synthetic fibers for some semi structural applications. The best approach to achieve environmental benefits is to use natural fiber in a natural resin matrix such as polylactic acid (PLA) from corn, polyhydroxybutyrate (PHB), starch based polymers, cashewnut shell liquid (CNSL) and natural rubber latex among others. Natural fibers such as hemp, flax, and wood have already found applications in the industries mainly asautomobile parts as presented by [6]-[11]. These natural fibers are readily available in abundance in every part of the world and can be easily recycled or degraded at the end of their life cycle allowing clean energy recoveries and environment.

Literatures on the use of banana stem and/or banana bunch fibers are very limited. These fibers from banana are emerging materials for composite manufacture with high conversion rate from agro-waste to high economic value products because banana fibers are available all year round and in every part of the world. Maleque et al. [12] studied pseudo banana fiber reinforced epoxy composite. Pothan et al. [13] studied the dynamic mechanical properties of banana fiber reinforced with polyester resin. Prasad et al. [14] found out that banana fiber reinforced with polyester has good tensile strength at 0.10 fiber volume fraction but with poor flexural properties. Kumar et al. reported that surface treatment of banana fibers resulted in a decrease in diameter but an increase in density [15] with improved mechanical properties.

The objective of this paper is to study the tensile properties of banana stem (trunk) fibers reinforced natural rubber composite so as to establish the usefulness or otherwise of the banana fibers as composite reinforcing materials. Emphasis is on the effect of surface treatment and fiber orientations on the tensile and morphological properties of the composite.

\section{Experimental}

\subsection{Materials}

A rettedbanana stem fibers (BSF) were obtained from Process Engineering and Environmental Technology Division, NIIST, Trivandrum, India. Natural rubber latex, $\mathrm{NaOH}, \mathrm{Na}_{2} \mathrm{SO}_{3}$ and other additives for natural rubber (NR) modification were supplied by Polymer Section, NIIST Trivandrum. Photographs of the raw BSF, extracted BSF and BSF-NR composites are shown in Figure 1.

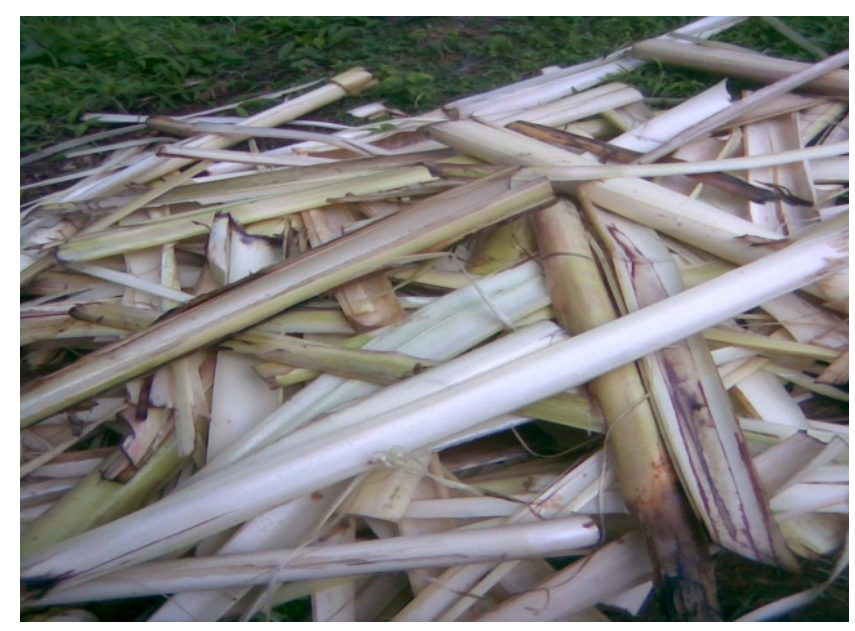

(a)

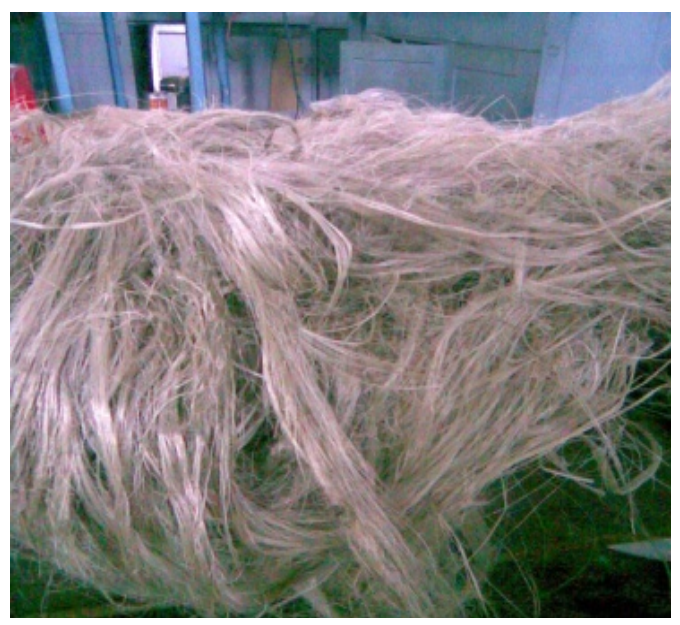

(b)

Figure 1. (a) Raw banana stem; (b) Extracted banana stem fibre. 


\subsection{Fiber Surface Treatment}

The surface of the retted banana stem fibers were soaked with $4 \% \mathrm{NaOH}$ and $2 \% \mathrm{Na}_{2} \mathrm{SO}_{3}$ solution for 24 hours. These fibers were washed with distilled water and dried under sun for 48 hours. To remove any trace of moisture, the fibers were further dried in an oven at $60^{\circ} \mathrm{C}$ for 1 hour.

\subsection{Matting of the Fibers}

Flat unidirectional arrangements of the fibers were made using raw natural rubber latex as the bonding agent. They were rolled to a fine thickness of about $1.2 \mathrm{~mm}$ and again dried in an oven at $60^{\circ} \mathrm{C}$ for 2 hours.

\subsection{Fabrication of the Composite}

The natural rubber matrix was prepared on a 3-roll mixing mill for about 3 minutes followed by addition of the modifiers such as anti-oxidantsand other additives as presented in Table 1. The mixing and milling were carried out for about 30 minutes and kept for 24 hours to allow proper cross linking. The nip gap, mill roll speed and the number of passes were kept the same for all mixes. The banana stem fibers were weighed and sandwitched between two layers of preweighed rubber sheets and then covered with polyethylene terephthalate (PET) sheets, this was cured in a metallic flat plate mold by compression molding on a hydraulic press (Model-INDUDYOG) for about 5 minutes at $150^{\circ} \mathrm{C}$ under pressure of $115 \mathrm{~kg} / \mathrm{cm}^{2}$. De-moldings was done at a very much lower temperature and allowed to cool off for at least 24 hours in an open air.

\subsection{Tensile Test}

After the composite was cooled, tensile test specimens were prepared according to ASTMD 638. The detailed dimensions, gauge length and cross head speed can be found at ASTM-D638 [16]. The specimens with a gauge length of $50 \mathrm{~mm}$ were tested on a tensile tester (Model-Hounsfield Tinus Olsen H5KS) at a cross head speed of $5 \mathrm{~mm} /$ minute without any strain gauge. Each specimen was loaded to failure. The force-extention curve was plotted automatically by the equipment software for the determination of the ultimate tensile strength and elastic modulus.

\subsection{SEM}

The morphological behavior of the tensile specimens were observed using scanning electron microscope (SEM) with equipment model-JOEL JSM-6100 after sputter coating the samples with gold for 45 seconds in a JOELJFC-1200 fine coater at a voltage of $12 \mathrm{kV}$. Micrographs were taken at various magnifications.

\section{Results and Discussion}

\subsection{Tensile Properties}

Table 2 and Figure 2 presents the results obtained from the tensile test of the specimens. The results indicated that the strength of the natural rubber was increased due to its reinforcement with BSF. The results also indicates

Table 1. Formulation of the mixes (modified natural rubber).

\begin{tabular}{cc}
\hline Ingrident & Qantity (g) \\
\hline Natural rubber & 200 \\
Zinc oxide & 10 \\
Stearic acid & 4 \\
MBT & 4 \\
Surphur & 4 \\
China clay & 20 \\
Antioxidant & 2 \\
\hline
\end{tabular}




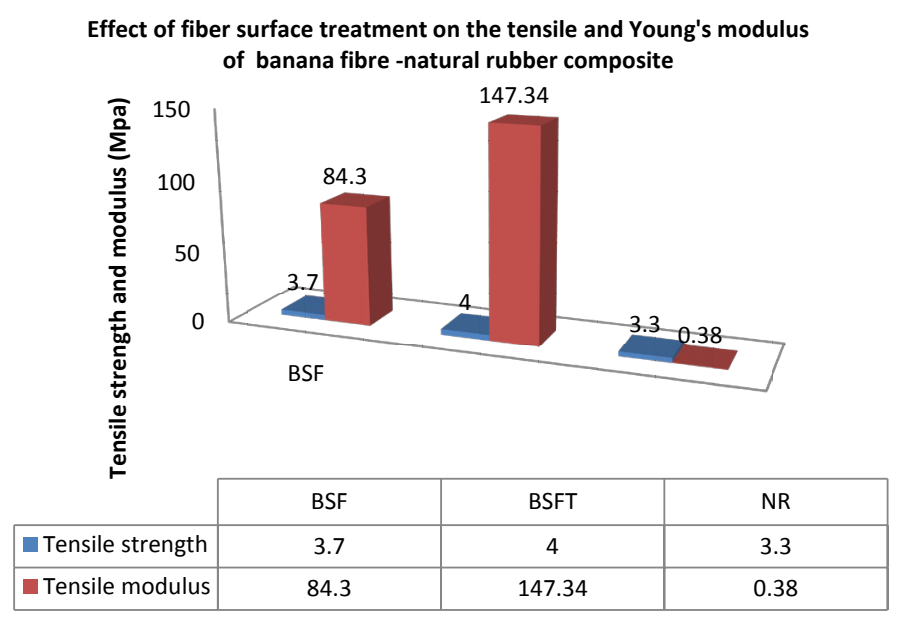

Figure 2. Effect of fiber surface treatment on the tensile strength and Young's modulus of banana fiber-natural rubber composite.

Table 2. Nomenclature of fibre surface treatment and orientation for the banana-NR composite.

\begin{tabular}{cccc}
\hline Sample code & Surface treatment status & Ply angle (degrees) & Max force (N) \\
\hline BSF & Untreated & $0^{\circ}$ & 20.8 \\
& & $45^{\circ}$ & 6.20 \\
BSFT & Treated & $90^{\circ}$ & 7.8 \\
& & $0^{\circ}$ & 42.3 \\
& & $45^{\circ}$ & 0.6 \\
NR & Unreinforced & $90^{\circ}$ & 2.0 \\
\hline
\end{tabular}

that the longitudinal ultimate tensile strength $\left(\sigma_{\mathrm{L}}\right)$ at 0.30 fiber mass fraction of untreated BSF-NR composite was 3.12 MPa while that of treated BSF-NR composite of the same lamina thickness was 4.03 Mpa with their Young's moduli of $84.30 \mathrm{MPa}$ and $147.34 \mathrm{MPa}$ respectively indicating a substantial improvement in the stiffness of the composite due to surface treatment.

Again it can also be deduced from Figure 3 that the strength of the composite is higher in the fiber longitudinal direction than the strength in the transverse direction of $90^{\circ}$ or any other angle such as $45^{\circ}$. As the orientation of the fiber increases from zero, the strength of the composite begins to drop up to $45^{\circ}$ and then it starts to increase again for the untreated. This indicates the anisotropic behaviour of the composites, while unreinforced natural rubber has the same strength in all directions indicating isotropic behavior.

Also Figure 3 indicated that the treated fibers however had decreasing strength as the angle of orientation increased up till $45^{\circ}$ and decreased further up to $90^{\circ}$. Again high degree of fiber orientation renders the effect of reinforcement useless as the resulting strength of the composite is very much lower than that of unreinforced natural rubber.

From Figure 4, the pattern of effect of orientation on the failure strength is similar to that found in Figure $\mathbf{3}$ however all the failure stress is very much lower than that of the natural rubber which is an indication that at failure the contributions of the reinforcements are no longer felt instead it is the matrix that is carrying the loads all alone. Again as the fiber orientation angle increases the failure strength of the composite decreases for both treated and untreated BSF-NR composites.

From Figure 5, the elongation at break of the natural rubber was observed to be very much higher than that of all the reinforced composites which increased as the fiber orientation angle increased. Again, the elongation at break of the untreated samples was slightly higher than that of the treated samples as the angle of orientation increased from $45^{\circ}$ to $90^{\circ}$. 


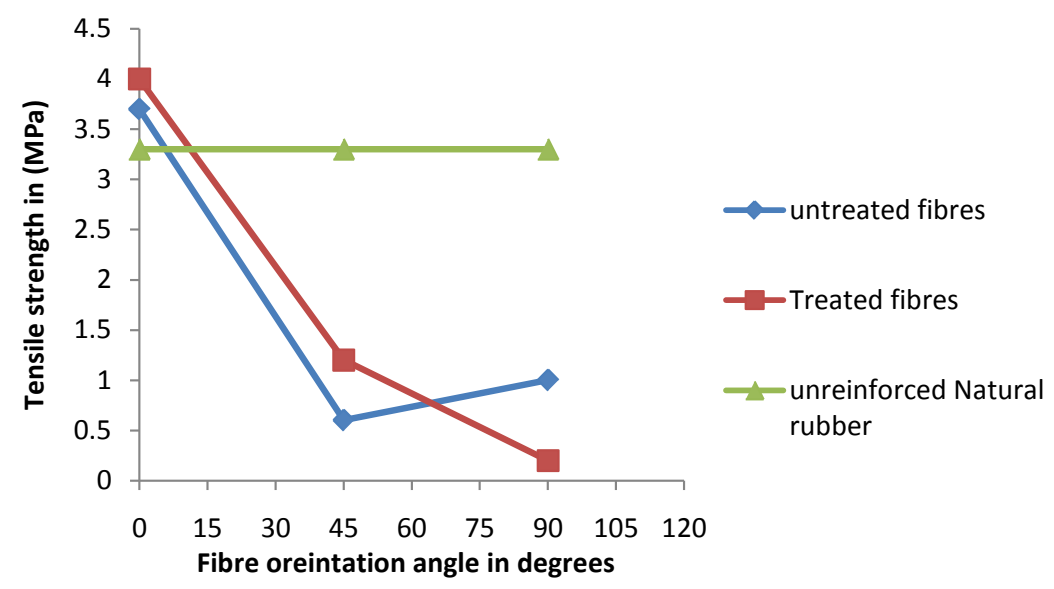

Figure 3. Effect of fibre treatment and orientation on the ultimate tensile strength of banana fibre-NR composite.

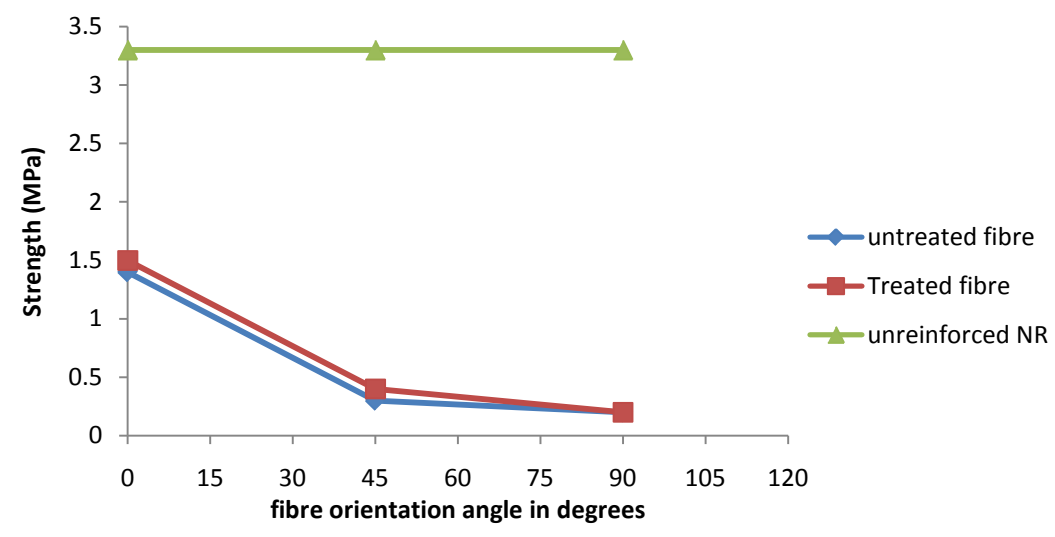

Figure 4. Effect of fibre treatment and orientation on the failure strength of banana fibre-NR composite.

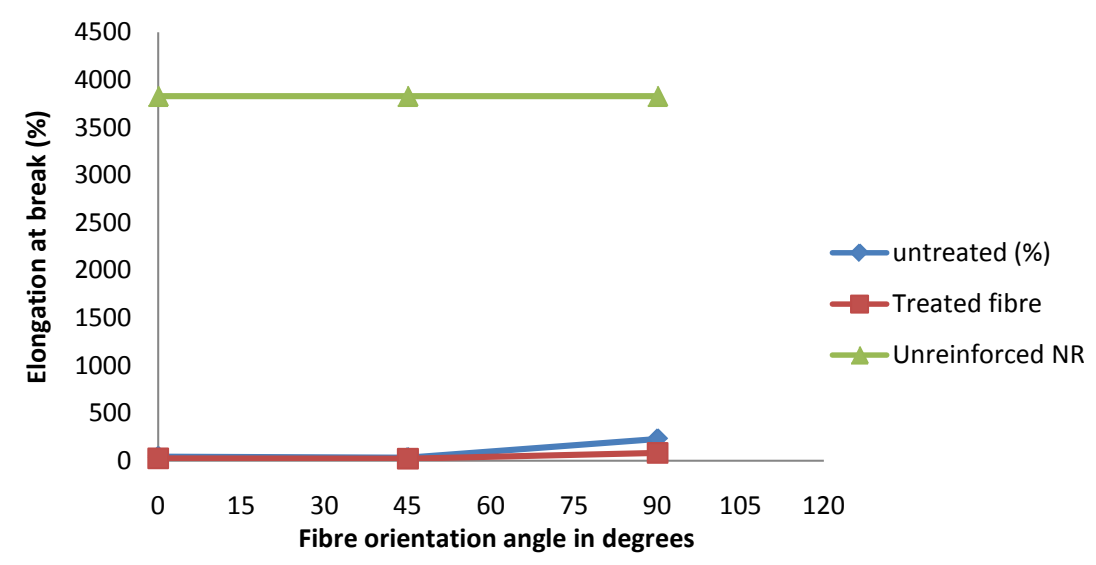

Figure 5. Effect of fibre treatment and orientation on the elongation at break of banana fibre-NR composite.

\subsection{Surface Treatment Study}

Figure 6(a) and Figure 6(b) present respectively the surfaces of the untreated banana and treated banana fibers prior to use for reinforced of natural rubber composites. In Figure 6(a) we can see the strands of the fibers segregate out clear compared to that of Figure 6(b) which shows agglomerations of the fiber bundles which gives 


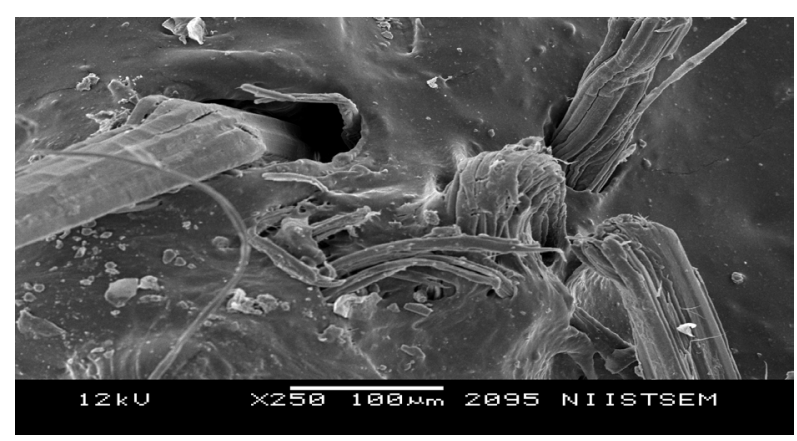

(a)

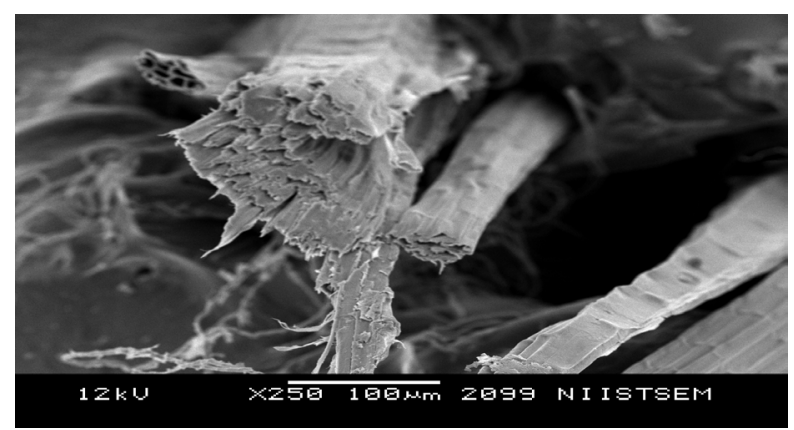

(b)

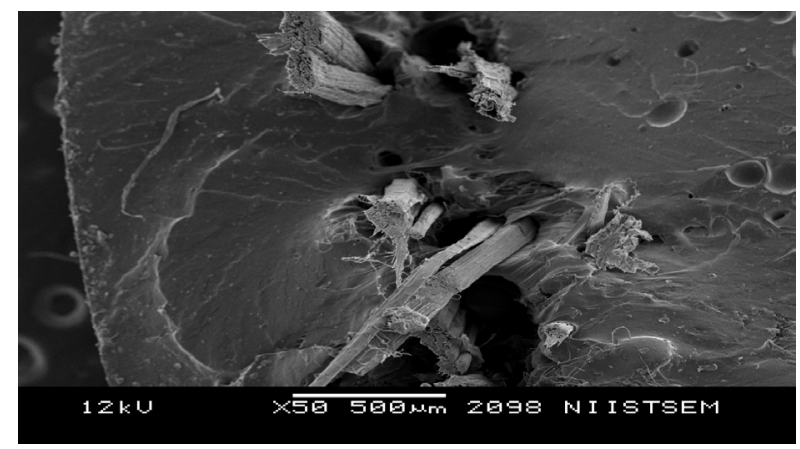

(c)

Figure 6. Fracture micrographs (a) Untreated BSF-NR composite $\times 50$; (b) Treated BSF-NR composite $\times 250$; (c) Treated BSF-NR composite $\times 50$.

a form of bonding prior to proper bonding with the rubber matrix. Figure 6(b) shows an improvement which may be due to fiber treatment, a strong bonding was noticed due to the fiber breakage instead of pullout or unwinding.

\section{Conclusion}

An investigation into the tensile and morphological properties of banana stem fiber reinforced natural rubber compsosite was presented. The strength and modulus were found to increase upon reinforcement of the natural rubber with banana fibers. The chemical modification of the banana fibers resulted in yet further improvement in the properties of the composite. The angle of fiber orientation to the loading direction was found to have significant effect on the tensile strength, failure strength and elongation at break of the composites. The combination of $\mathrm{NaOH}$ and $\mathrm{Na}_{2} \mathrm{SO}_{3}$ in fiber surface treatment indicated good bondingfrom the SEM result, which iscontrary to the report by Maya et al. [17] when only $\mathrm{NaOH}$ was used. The composite may not be useful in applications that requires high tensile loading because of its low tensile strength but will be useful at low tensile loading or under compressive loading such as in ceiling or floor tiles and parapet wall tiles as shown in Figure 1(c). 


\section{Acknowledgements}

This research was jointly funded by Indian National Science Academy (INSA), New-Delhi through Centre for International Cooperation in Science (CICS) formerly CCSTDS Chennai India and National Institute for Interdispilinary Science and Technology (NIIST-CSIR) Trivandrum, India as part of INSA-JRD-TATA FELLOWSHIP Training, June-August, 2010. We are therefore very grateful to the management and staff of these sponsoring organizations.

\section{References}

[1] Maya, J.J. and Sabu, T. (2010) Cellulosic Fibril-Rubber Nanocomposite; Rubber Nanocopmosite: Prepartions, Properties and Applications. John Wiley \& Sons Asia Plc Ltd, 197-209.

[2] Han, Y.H., Han, S.O., Cho, D. and Kim, H.-I. (2008) Dynamic Mechanical Properties of National Fiber/Polymer Composites-The Effect of Fiber Treatment with Electron Beam. Macromolecular Research, 16, 253-260. http://dx.doi.org/10.1007/BF03218861

[3] Pritchard, G. (2004) Two Technologies Merge: Wood Plastic Composite. Journal of Plastic Additives and Compounding, 48, 26-29.

[4] Satyanarayana, K.G., Pai, B.C., Sukumaran, K. and Pillai, S.G.K. (1990) Fabrication and Properties of Lignocellulosic Fiber-Incorporated Polyester Composites. Handbook of Ceramics and Composites, Vol. 1, Synthesis and Properties. Marcel Dekker Inc., New York, 339-384.

[5] Ticoalu, A., Aravinthan, T. and Cardona, F. (2010) Review of Current Developments in Natural Fiber Composites for Structural and Infrastructure Applications. Southern Region Engineering Conference, Toowoomba, 11-12 November.

[6] Fan, M. (2010) Characterization and Performance of Elementary Hemp Fiber: Factors Influencing Tensile Strength. Bioresources, 54, 2307-2322.

[7] Misra, M., Mohanty, A.K. and Drzal, L.T. (2002) Opportunities and Cchallenges in the Materials World. Plastic Impact on the Environment, Detroit, 13-14 February, 383-398.

[8] Oladele, I.O., Akinwekomi, A.D., Arobo, S. and Aladenika, A.K. (2009) Development of Fiber Reinforced Cementitious Composite for Ceiling Application. Journal of Minerals and Materials Characterization \& Engineering, 8, 583590.

[9] Esmeraldo, M.A., Gomes, A.C., Freitas, J.E.B., Fechine, P.B.A., Sombra, A.S.B., Corradini, E., Mele, G., Maffezzoli, A. and Mazzetto, S.E. (2010) Dwalf-Green Coconut Fibers: A Versatile Natural Renewable Raw Bioresource: Treatment, Morphology and Physico-Chemical Properties. Bioresources, 5, 2478-2501.

[10] Amer, A.A., Azza, E., Malash, G.F. and Nahla, A.T. (2007) Extensive Characterization of Raw Barley Straw and Study of the Effect of Steam Pretreatment. Journal of Applied Science Research, 3, 1336-1342.

[11] Dai, D. and Fan, M. (2010) Characteristics and Performance of Elementary Hemp Fiber. Materials Science and Applications, 1, 336-342. http://dx.doi.org/10.4236/msa.2010.16049

[12] Maleque, M.A., Belal, F.Y. and Sapuan, S.M. (2006) Mechanical Properties Study of Pseudo-Stem Banana Fiber Reinforced Epoxy Composites. The Arabian Journal of Science and Engineering, 32, 359-364.

[13] Pothan, L., Sabu, T. and Zachariah, O. (2003) Dynamic Mechanical Analysis of Banana Fiber Reinforced Polyester Composites. Composite Science and Technology, 63, 137-152.

[14] Prasad, A.V., Mohana Rao, K. and Nagasrinivasulu, G. (200) Mechanical Properties of Banana Empty Fruit Bunch Fiber Reinforced Polyester Composite. Indian Journal of Fiber \& Textile Research, 34, 162-167.

[15] Kumar, S. and Misra, R.K. (2007) Analysis of Banana Fiber Reinforced Low-Density Polyethylene/Poly(E-caprolactone) Composites. Soft Materials, 4, 1-13. http://dx.doi.org/10.1080/15394450600823040

[16] ASTM D638-10 (2010) Standards Test Method for Tensile Propeties of Plastics: Annual Book of ASTM Standards. June 2010 Edition. www.astm.org.pdf

[17] Jacob, M., Jose, J., Jose, S., Varaghese, K.T. and Thomas, S. (2010) Viscoelastic and Thermal Properties of SisalFabric Reinforced Natural Rubber Biocomposite. Journal of Applied Polymer Science, 117, 614-621. 